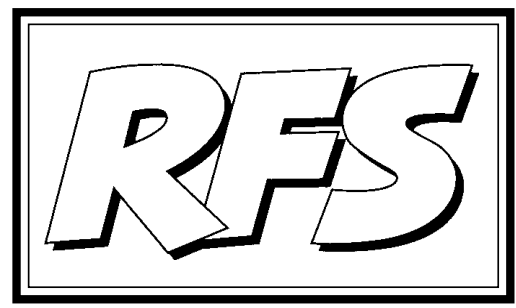

Revista de Fomento Social, 53 (1998), 69-90

\title{
Las relaciones económicas entre la Unión Europea y los países del Sur y del Este del Mediterráneo
}

Las perspectivas de la ampliación de la Unión Europea hacia los países del Este acaparan con frecuencia los debates comunitarios. Ello se observa, por ejemplo, de forma especial en los documentos y propuestas emanados en el marco de la llamada Agenda 2000. Pudiera dar la impresión (falsa) de que se estuviera produciendo un cierto «olvido» comunitario de la vertiente sur del mediterráneo. Contemplada desde España, «territorio de contacto» donde los haya con el Mediterráneo sur, esta evolución no puede hacernos olvidar nuestra vecindad, manifestada de forma cotidiana, entre otras cosas, en el permanente «asalto» de las pateras cargadas de africanos del norte (y no tan del norte) que buscan en nuestras costas un lugar de desembarco en la «tierra prometida» europea. Las relaciones económicas, políticas y culturales entre la $\mathrm{UE}$ y los países del sur y del este del Mediterráneo deben, por tanto, seguir ocupando un lugar prioritario en la agenda europea. El artículo siguiente nos lo recuerda. Jean DUCRUET (*)

(*) Jesuita. Universidad de San José de Beyrut (Líbano). Texto de la conferencia 
Para evocar los problemas de las relaciones económicas entre la UE y los países del sur y del este del Mediterráneo, voy a recordar de manera sucesiva las variables demográficas, comerciales, financieras y políticas que permiten ilustrar estos problemas. También voy a precisar al menos una parte del contexto de las propuestas de las conferencias euromediterráneas de Barcelona en noviembre de 1995 y de Malta en abril de 1997, tan marcadas por el temor europeo de ver intensificarse la inmigración. Desde el punto de vista económico, estas propuestas se refieren esencialmente a la constitución de una zona de libre comercio entre la Unión Europea y otros países ribereños del Mediterráneo; de esta manera la zona podría llegar a ser cada vez más atractiva para las inversiones, favoreciendo los intercambios entre el norte y el sur, así como entre los países mismos del sur, y haciendo así en buena parte caducos los flujos migratorios hacia Europa.

\section{Los datos demográficos y las migraciones que provocan}

En la base de los desequilibrios entre las dos riberas del Mediterráneo, hay un fuerte contraste demográfico. La orilla norte pasó de un régimen de altas tasas de mortalidad y fecundidad a un régimen de bajas tasas de mortalidad y fecundidad; en las orillas sur y este, ese proceso ha comenzado pero está muy lejos de culminar. De esta dinámica resulta una situación de estancamiento demográfico en una orilla y de fuerte crecimiento demográfico en la otra. En 1950, dos tercios de los habitantes del Mediterráneo vivían en la ribera norte; en 1990, todavía la mitad viven en esa orilla norte; pero en el año 2025, solo un tercio vivirá en ella. Entre 1990y 2025, los países árabes de las orillas sury este habrán aumentado su población en un $90 \%$, Turquía en un $61 \%$, mientras que los países europeos de la orilla norte solamente crecerán un $6 \%$. Este desfase demográfico entre las dos riberas del mediterráneo aumentará todavía más el desfase de sus rentas: en 1992, elPIB por habitante era doce veces superior en la Europa comunitaria al de los países del sur y del este del Mediterráneo; según las proyecciones más favorables del Banco Mundial, la relación será de 20 contra 1 el año 2010 (1).

pronunciada en el Congreso de EUROJESS (Jesuitas europeos en Ciencias Sociales) de Palermo, julio de 1997. Traducido del francés por José J. Romero.

(1) Bichara KHADER, Le Partenariat euro-méditerranéen, CERMAC, Louvain 1995, p.55. 
Los países del sur y del este del Mediterráneo experimentan ya una caída de sus tasas de fecundidad. En diez años han bajado notablemente: un tercio en Turquía y un cuarto en Marruecos; pero estos países sufrirán todavía durante veinte años una fuerte presión sobre el mercado de trabajo y un crecimiento de la emigración. ¿Cómo se presenta actualmente esta emigración hacia Europa? Los países de la Comunidad Europea, cuya población ascendía a unos 340 millones de habitantes en 1990, tenían censados 5 millones de ciudadanos de otros países pertenecientes a la Comunidad y 6,5 millones de ciudadanos de países no europeos; de ellos el 65\% provenían del Magreb y de Turquía. En 1994, 2,5 millones de turcos residían en la Comunidad Europea, de los cuales cerca de dos millones estaban en Alemania. Marruecos contaba con más de un millón, de los cuales 610.000 residían en Francia, 160.000 en los Países Bajos, 140.000 en Bélgica, 100.000 en Italia y 15.000 en España. Argelia contaba con 650.000, de los cuales 620.000 residían en Francia. Túnez tenía 300.000 emigrantes, de ellos 200.000 residían en Francia y 45.000 en Italia (2). Estas cifras sólo se refieren a los inmigrantes regularmente inscritos y que siguen siendo extranjeros.

¿En qué contexto de política de los países de acogida se sitúan estas migraciones de los países del sur y del este del Mediterráneo? Los países europeos han conocido una sucesión de fases de emigración bastante semejantes. En los años 60, la inmigración estaba ligada a las importantes necesidades de mano de obra de un periodo que en Europa se caracterizaba por la recuperación y la expansión. La crisis económica de mitad de los años 70 detiene en buena parte esta entrada de extranjeros. Se pasa entonces a una inmigración sedentarizada con lo que ello implica de reagrupamiento familiar. En los años 80 se agudizan los problemas de la segunda generación de inmigrantes, y se desarrolla una política de integración encaminada, según los países, sea a la asimilación de los extranjeros, incluida la cultural, sea a su inserción comunitaria procurando preservar su identidad cultural. Esta política de integración tiene como contrapartida la exigencia de dominar los flujos migratorios en función de las posibilidades de los países de acogida. La firma en junio de 1990 de la convención de aplicación del acuerdo de Schengen, que suprime gradualmente los controles en las fronteras interiores de la Comunidad Europea, refuerza la

(2) David COLEMAN, «Les flux d'immigrants en Europe» en La Population du Monde édité para J.C. CHASTELAND et J.C. CHESNAIS, PUF, 1997. 
exigencia de estos controles en las fronteras exteriores (3). A las limitaciones que se instauraban de esta forma, se añaden entonces los proyectos de ayuda al desarrollo de los países exportadores de mano de obra, para reducir la necesidad de emigración (4).

¿Cuáles son los efectos de estas migraciones en los países del sur y del este del Mediterráneo? Por una parte, las migraciones disminuyen el paro en estos países; este desempleo se sitúa entre el 25 y el $30 \%$ de la población activa. Por otra parte, los emigrados efectúan substanciales transferencias financieras hacia sus países de origen. Acumulados desde 1971 a 1992, los flujos netos de estas remesas provenientes de Europa representan 34 mil millones de dólares en los tres países del Magreb y 39 mil millones en Turquía. En el Magreb, esta aportación ha sido 7 veces más elevada que las inversiones extranjeras; en Turquía las remesas de emigrantes cubren el 50\% del déficit comercial (5).

¿Cómo se utilizan estas entradas de divisas? Los economistas ponen de relieve con frecuencia que el ahorro transferido de la emigración va esencialmente al consumo o a la construcción, estimulando la importación y no precisamente la capacidad productiva de los países del sur y del este del Mediterráneo, que sería necesaria sobre todo en materia de exportaciones industriales. Sin embargo, no se puede valorar la aportación de la emigración mediante una referencia tan parcial. Muchos sectores, por ejemplo, de la pequeña agricultura y del artesanado deben enteramente su equipamiento a los emigrantes. El aumento del consumo familiar debido a las remesas de emigrantes muestra simplemente la amplitud de una demanda no satisfecha de bienes de consumo en esos países; de la misma forma, el incremento de las construcciones puede estar indicando lo reducido del abanico de oportunidades de inversiones rentables para los pequeños capitales. La movilización del ahorro de los emigrantes sigue siendo en todo caso un problema muy importante. Y lo será

(3) Cf. «Les politiques d'immigration en Europe». Problèmes politiques et sociaux, n 673, 7 février 1992, et Immigrés en Europe sous la direction de Didier LAPEYRONNIE, Documentation Française 1992.

(4) Pierre GUENGANT, «Migrations internationales et développement: les nouveaux paradigmes» en Revue européenne des migrations internationales, $2^{\circ}$ semestre 1996.

(5) Jacques Ould AOUDIA, «Les enjeux économiques de la nouvelle politique méditerranéenne de l'Europe» en Monde arabe, Maghreb Machrek, $\mathrm{n}^{\circ}$ 153, juilletseptembre 1996, p. 30. 
todavía más si se confirma la tendencia hacia una reinversión parcial del ahorro de la emigración en los propios países de acogida. «No hay que extrañarse, se ha escrito, de ver hoy en Europa a hijos de emigrantes turcos, marroquíes o tunecinos a la cabeza de verdaderas empresas... Sería deseable movilizar no sólo el ahorro de los inmigrantes sino también los capitales de este nuevo grupo de empresarios de origen mediterráneo en proyectos de joint-ventures industriales...»

Quizás no esté de más destacar, para terminar esta pequeña introducción sobre las migraciones hacia Europa, que su impacto no puede medirse únicamente en términos financieros. La emigración modifica en los propios emigrantes muchos comportamientos y sus propias jerarquías de valores; estos procesos no carecen de importancia desde la óptica del desarrollo económico y social de los países del sur y del este del Mediterráneo. Se ha calificado a los emigrantes de «pasadores de culturas» (7) evocando en particular su influencia en la evolución del status familiar y demográfico de sus países de origen y sobre su propio comportamiento económico. En algunos aspectos, se podría hablar de ósmosis de civilizaciones. ¿Acaso es posible ignorar estos fenómenos y seguir hablando de cooperación y complementariedad como si se limitara en la práctica a la libre circulación de mercancías y de capitales?

Por otro lado, las conferencias euro-mediterráneas suscitan la esperanza de unificar a los países del sur del Mediterráneo en una vasta zona de libre comercio. Esto no es ciertamente realista a corto plazo, en particular por la ausencia de complementariedad económica de estos países y por la ausencia de disparidad de nivel tecnológico entre ellos mismos. Los intercambios, por ejemplo, de Egipto con los otros países del Próximo y del Medio Oriente no representan sino el 3\% de sus flujos comerciales; Túnez, el país más abierto hacia su entorno inmediato, llega apenas a efectuar un 5\% de sus intercambios con sus vecinos. Pero si bien esta región no conoce apenas la circulación de bienes, sin embargo presenta una intensa circulación de personas. Los Estados de la península arábiga han acogido hasta 5,5 millones de trabajadores extranjeros, lo que

(6) Bichara KHADER, op. cit. p.40.

(7) Youssef COURBAGE, «Le Maroc de 1962-1994; fin de l'explosion démographique», en Monde arabe, op. cit, p. 81. Véase igualmente «L'imigration turque au féminin» en Cahiers d'études sur la Méditerranée Orientale et le Monde Turco-iranien, no 21, 1996. 
representa un tercio de la población residente; Irak, antes de la guerra del Golfo, tenía 1 millón de inmigrantes; después Libia lo ha reemplazado. Los flujos financieros ligados a la circulación de personas entre los países del sur y del este del Mediterráneo son tres veces superiores a los del comercio interregional. Más allá de este impacto financiero, estas migraciones interiores tienen un impacto social y cultural considerable; este impacto puede ser peligroso si los países del islamismo duro se convierten en la única vía de emigración de los países del islamismo mediterráneo.

En cualquier caso, la movilidad de las personas, que tiene causas y consecuencias complejas, es un dato fundamental de esta región del mundo, que exige un estudio detenido y una visión global de los problemas planteados. No debería ser tratada simplemente como una deficiencia a eliminar, sobre todo en una época en que tanto se defiende la mundialización de los intercambios (8)...

\section{Los datos comerciales y la liberalización de los intercambios}

Los intercambios comerciales entre Europa y los países del sur y del este del Mediterráneo se caracterizan, como ocurre con las relaciones demográficas, por un profundo desequilibrio. Por una parte, estos intercambios son asimétricos, lo que no tiene nada de extraño a la vista del desfase del peso económico de los dos conjuntos: los intercambios con los países del sur y del este del Mediterráneo representan menos del 5\% del comercio de la Unión Europea, mientras que suponen más del 50\% de los intercambios de estos países. Por otra parte, estos intercambios están desequilibrados: el saldo de la balanza comercial de estos países en beneficio de Europa es, por ejemplo en 1993, de 17,8 miles de millones de dólares para todos los productos; de 24,3 miles de millones de dólares para solamente los productos manufacturados (excluyendo, por tanto, los hidrocarburos), a pesar del hecho de que para sus productos Europa ha concedido a sus socios, de forma unilateral, el libre acceso a su mercado. La eliminación de los

(8) Bruno CABRILLAC, «Mobilité des hommes et immbolité des biens au MoyenOrient» en L'économie de la paix au Proche-Orient, bajo la dirección de Louis BLIN et Philippe FARGUES, Maisonneuve et Larose 1995 T. 1. pp. 165-180. Robert ESCALLIER, «Populations et systèmes migratoires du Monde Arabe» en Maghreb, Moyen-Orient, mutations édité par Jean-Francois TROIN, Sedes 1995. 
derechos de aduanas y de las restricciones por parte de los países del sur y del este del Mediterráneo en sus intercambios industriales con Europa, preludio al establecimiento previsto de una zona de libre comercio, tiene todavía el peligro de agravar su déficit comercial. Este déficit será tanto menos abordable cuanto Europa sigue siendo por el momento proteccionista en lo relativo a los intercambios agroalimentarios; eso no tiene nada de extraño dado que la agricultura es el ámbito por excelencia de la integración europea: los intercambios intracomunitarios representan, en 1993, el 66\% del conjunto de los intercambios agroalimentarios europeos frente a sólo el $38 \%$ de veinte años atrás.

Sin embargo, la estructura de las exportaciones hacia Europa no es idéntica para todos los países. Turquía, Túnez y Marruecos han sabido aprovecharse desde los años 80 del sistema de preferencias que les concedía la Comunidad Europea; esto les permite establecer con la Comunidad intercambios propios de países en vías de industrialización; ello les permite hoy día, a pesar de los riesgos, comprometerse en la vía de la liberalización de los intercambios. Pero ése no es el caso, por ejemplo, de Argelia y Egipto cuyos intercambios siguen siendo típicos de países en vías de desarrollo, y están marcados por la primacía de las exportaciones de productos primarios (hidrocarburos, a los cuales en el caso de Egipto hay que añadir el algodón bruto). En seguida voy a evocar brevemente la historia de estos diversos países para subrayar las dificultades de la propuesta europea de zona de libre comercio.

Marcada durante mucho tiempo por la voluntad kemalista de construir una nación turca y una economía nacional, hasta el comienzo de los años 80 TURQUIA ha seguido una política económica proteccionista basada en la sustitución de las importaciones a partir de producciones industriales locales, basada también en la puesta en marcha de empresas estatales potentes, en una fijación imperativa de precios y de rentas, y en el control del tipo de cambio. A pesar de los primeros éxitos de esta política, las dificultades se multiplicaron: aparecieron distorsiones entre sectores, penurias de bienes de equipo, recalentamiento inflacionista. Estas dificultades, unidas al brusco encarecimiento de las importaciones petrolíferas, el peso de la deuda externa, y el haber acometido imprudentes programas de inversión pública condujeron a Turquía, después del golpe de estado militar de 1980, a un cambio radical de política económica; pero, a diferencia de otros países, Turquía lo hizo, felizmente para ella, sobre la base de una industria ya desarrollada para su propio mercado, gracias a una efectiva 
protección aduanera.

La política resueltamente liberal de los años ochenta, emprendida en particular con el fin de preparar el acuerdo de unión aduanera entre Turquía y la Unión Europea, defendió la iniciativa privada y la apertura hacia el exterior. Se apoyó en la abolición del control de cambios y en la libre convertibilidad de la libra turca, así como en un código de inversiones muy liberal, y en una privatización parcial del sector público. Se registraron resultados bastantes espectaculares: el PNB experimentó un crecimiento medio del 5,3\% anual y el comercio exterior más del $11 \%$; la participación de los productos industriales en las exportaciones pasó del 30\% en 1980 al 78\% en 1990; el número de empresas extranjeras instaladas en Turquía pasó, en diez años, de 109 a 2.400, el 57\% de las cuales provenían de la Comunidad Europea. El balance de este periodo no está sin embargo desprovisto de aspectos negativos: incremento de los préstamos, desarrollo demasiado rápido de las importaciones lo que desequilibró la balanza comercial, y desviaciones presupuestarias. La política liberal y el desarrollo acelerado - que han sido calificados como «marcha forzada hacia Europa»-fueron interrumpidos de forma provisional por la crisis económica de 1994. Después de haber alcanzado un acuerdo con el Fondo Monetario Internacional, Turquía reaccionó con el vigor de costumbre: disminución del $40 \%$ de los salarios, despidos masivos, doble devaluación de la libra turca, interrupción provisional de todos los programas de inversión. El crecimiento económico volvió a darse en 1995, a pesar de una fuerte inflación. Uno de los dirigentes de Renault, tercera empresa privada de Turquía, que había perdido la mitad de sus ventas y reducido su personal de una manera drástica, comentaba: «Estamos en Turquía, no en Europa, y la capacidad de adaptación de esta sociedad es fantástica» (9). Seguramente que la población turca habría acogido este juicio con muy serias reservas...

El acuerdo de unión aduanera entre la Unión Europea y Turquía fue firmado el 6 de marzo de 1995 y entró en vigor el primero de enero de 1996. Ello implicaba para estas fechas la eliminación de todos los derechos de aduanas de restriccio-

(9) Nicolas BEAU «Turquie: la marche forcée vers l'Europe» en L'Expansion, Paris n 499, 14 avril 1995 p. 112. Sobre la situación económica de Turquía, cf. Etudes économiques de l'OCDE, Turquie 1995-1996. Semih VANER, «Turquie: la nouvelle donne» en Problèmes politiques et sociaux no 75710 novembre 1995. 
nes cuantitativas en los intercambios de productos industriales con la Unión Europea, la aplicación de la tarifa exterior común de la Unión Europea con respecto a los países terceros de aquí al año 2010 y la adopción de reglas europeas en materia de competencia, incluyendo las medidas relativas a las ayudas públicas, en un plazo de dos a cinco años. Los intercambios en el terreno de la agricultura, los movimientos de capitales y de mano de obra serán objeto de acuerdos que aún siguen en estudio.

La historia de la economía de MARRUECOS y de TÚNEZ durante las tres últimas décadas y de sus relaciones comerciales con Europa no deja de tener analogía con la de Turquía. Esta historia está constituida igualmente ante todo por una fase proteccionista, orientando las medidas proteccionistas a asegurar los ingresos del Estado así como a la protección de las industrias nacionales. Pero, al disminuir las importaciones por el incremento de los precios, este proteccionismo terminó igualmente reduciendo la competitividad de las exportaciones y limitándolas a los recursos naturales. La caída de los precios del fosfato marroquí en 1976, la bajada de la producción de hidrocarburos en Túnez desde comienzos de los años ochenta y luego las bajadas de los precios del petróleo forman parte de las causas que conducen a estos dos países a abrirse de nuevo y a promover la liberalización de los intercambios, con la ayuda del FMI.

Marruecos y Túnez optaron entonces de forma clara por una economía manufacturera y exportadora necesitada de ajustes estructurales y por una política de privatización. Así, la importancia relativa de los productos manufacturados en las exportaciones de Marruecos hacia Europa pasa del 34\% en 1988 al 68\% en 1993; en Túnez este porcentaje pasa del 66\% en 1989 al 83\% en 1993. Entre 1988 y 1993, las exportaciones totales de Túnez hacia la Comunidad Europea se duplicaron y las de Marruecos aumentaron en dos tercios. Así es como estos dos países, explotando las ventajas de sus menores costes salariales, desarrollan sus exportaciones de productos manufacturados. Prosiguió la liberalización de las importaciones por etapas. En 1993, los derechos y las tasas aparentes sobre las importaciones representan todavía el 20\% en los dos países, mientras que ya no son sino del $5 \%$ en Turquía. Y es que su supresión disminuiría de un tercio a un cuarto los ingresos de la administración pública de estos países. La firma por Túnez en noviembre de 1995 y por Marruecos en febrero de 1996 de un acuerdo que conduce a estos países hacia la constitución de una zona de 
libre comercio les compromete a nuevos ajustes económicos (10).

Esta rápida visión sobre la historia comercial de Turquía, de Marruecos y de Túnez, tres países que están embarcados en una apertura económica, demuestra al menos que el proceso de liberalización al final de una etapa de proteccionismo comporta riesgos importantes de desestabilización. Implica la reasignación de los factores de producción, lo cual supone una capacidad de adaptación de las empresas, su acceso a las inversiones y la existencia de recursos humanos adecuados. Por otra parte implica también que se tomen opciones de economía nacional: que el gobierno decida o no aumentar la fiscalidad para compensar las pérdidas de los ingresos derivadas de la supresión de los derechos de aduanas, que decida o no una bajada compensadora de los gastos públicos, que actúe o no sobre el tipo de cambio para controlar las transacciones; todas estas opciones modifican profundamente el proceso de liberalización y determinan su coste humano.

EGIPTO conoció también una tentativa de política de apertura después de la guerra de 1973: llamada a la inversión privada, nacional o extranjera, reducción del sector público, supresión del control de los tipos de cambios. Las nuevas orientaciones, reforzadas en 1976 por la intervención del FMI, son abandonadas al año siguiente, como consecuencia de las agitaciones y de las protestas que se levantaron contra la reducción de las subvenciones alimenticias. El boom de la producción petrolífera y las transferencias de los emigrantes del Golfo evitan el tener que tomar opciones económicas y permiten una recuperación de las inversiones; sin embargo las deudas no tardan en tomar el relevo del ahorro nacional. En 1987, la deuda egipcia representa cinco veces y medio el Producto Nacional Bruto. Los programas de reforma, acordados con el FMI como contrapartida de un cierto aligeramiento de la deuda, tropiezan de nuevo con el descontento popular. La crisis del Golfo en 1990 invierte esta vez de nuevo la situación: llegada de ayuda, anulación de la deuda militar con respecto a los Estados Unidos y de la deuda con respecto a los países del Golfo (en total más

(10) Véase, en particular Abdelkader SID AHMED, «La crise des économies maghrébines» en Tiers Monde, juillet-septembre 1993 et octobre-décembre 1993. Gérard KEBABDJIAN «Le libre échange euro-maghrébin» ibd., octobre-décembre 1995, Denis COGNEAU et Georges TAPINOS, «Libre-échange, répartition du revenu et migration au Maroc» en Revue d'Economie du développement 1/1995. 
de 10 mil millones de dólares), escalonamiento de las otras deudas. Sería necesaria la promoción de exportaciones no tradicionales para evitar que se repita el ciclo de los déficits corrientes y de las devaluaciones; pero las ya habituales recuperaciones procedentes del exterior, gracias a las rentas económicas y políticas y a la buena voluntad de los Estados Unidos, no han permitido que se desarrolle en Egipto la voluntad política de un cuestionamiento del sistema económico.

En $\boldsymbol{A R G E L I A}$, la tentativa de liberalización de la economía es más corta todavía que en Egipto y el peso de la deuda fue más pesado. Hay que poner de relieve la fecha de julio de 1989 marcada por las leyes sobre los precios, sobre la moneda, sobre los monopolios de distribución, y sobre las relaciones laborales. Argelia se enfrenta en particular a la necesidad de reembolsar la deuda externa que en 1991 absorbía más del 70\% de las entradas de divisas del exterior. El 3 de junio de aquel año, se consigue una demora de la deuda con el apoyo del FMI. Como consecuencia de los sucesos políticos que sufre Argelia en 1992, el nuevo Gobierno suspende el acuerdo firmado con el FMI contando con el crecimiento de los ingresos por hidrocarburos para restablecer la situación. Quedan prohibidas las importaciones de productos que le hagan la competencia a la producción nacional; se revisa la ley sobre la moneda y el crédito; el presupuesto vuelve a las tradiciones de grandes déficits. En el umbral de 1994, el pago de los intereses de la deuda es superior por sí solo a todos los recursos en divisas del país. En el mes de abril de 1994 se firma un nuevo acuerdo de 4 años con el FMI: este acuerdo incluye una demora de los plazos de la deuda, una liberalización de los precios y del comercio exterior. Cuando se llegue a su fecha de vencimiento, en mayo de 1998, el acuerdo no podrá volver a prorrogarse. Pero Argelia tiene hoy los medios financieros para librarse del FMI, gracias a la recuperación de sus ingresos petrolíferos y del gas y a una severa reducción de sus importaciones, con lo cual espera recuperar su independencia económica (11).

Los otros países del sur del Mediterráneo están demasiado directamente implicados en el conflicto israelí como para poder hacer abstracción de este conflicto. Contentémonos con mencionar al LÍBANO. Después de una guerra que destruyó su infraestructura, este país intenta guardar durante cinco años su

(11) Isabelle BENSIDOUN et Agnès CHEVALLIER, Europe-Méditerranée, le pari de l'ouverture. Economica, 1996. pp. 48-64. 
libertad total, protegiendo la industria y la agricultura, antes de entrar en el período de doce años previsto por la Unión Europea para una supresión por etapas de los aranceles. Estos aranceles representan actualmente el 50\% de los ingresos del tesoro, y la instauración del IVA para compensar esta pérdida cae fuera de las posibilidades de la administración. Por otro lado, no se acaba de ver cómo el Líbano podría incrementar todavía más este déficit con la Unión Europea, que asciende ya cada año a unos 4.000 millones de dólares, enviándole mercancías solamente por valor de unos 200 millones de dólares. Por otro lado, la preocupación principal del país no es la constitución de una zona de libre comercio, sino la instauración de una era de paz y de independencia que permita el retorno de una parte de los emigrantes (en quince años los sectores productivos perdieron más del $40 \%$ de sus efectivos originales) y de las inversiones masivas que necesita su reconstrucción.

Egipto, Argelia y el Líbano nos recuerdan, por tanto, además de las observaciones ya hechas a propósito de Turquía, de Túnez y de Marruecos, que no se puede hacer abstracción de los datos financieros y de los datos políticos de los países afectados para promover en ellos la liberalización de los intercambios comerciales. Son precisamente estas claves las que debemos enumerar a continuación.

\section{Los datos financieros en sus dos vertientes: el endeudamiento y las inversiones extranjeras}

La reestructuración de la economía de los países del sur y del este del Mediterráneo necesita un esfuerzo muy importante de inversión; elloimplica una renegociación de la deuda de estos países y una aportación de capitales exteriores.

El endeudamiento internacional, cuando se maneja con la flexibilidad de los medios necesarios, puede ayudar al desarrollo económico y a la continuidad de los intercambios internacionales. Sin embargo, se plantea la cuestión, si no ya del nivel óptimo de endeudamiento de un país, al menos del umbral crítico a partir del cual un nivel de endeudamiento ya no es soportable porque perturba a la economía en lugar de ayudarle.

En 1985, la deuda exterior de los cinco países estudiados alcanzaba $91 \mathrm{mil}$ millones de dólares: 28,3 de Egipto; 25,5 de Turquía; 18,6 de Argelia; 13,4 de 
Marruecos; 5,2 de Túnez. En la década siguiente, el montante de esta deuda aumentó un 66\%, alcanzando en 1994 un total de 151 milmillones de dólares: 40,4 de Egipto; 54,8 de Turquía; 26,3 de Argelia; 21,4 de Marruecos; 8,4 de Túnez. Este endeudamiento representa el 92,4\% del Producto Interior Bruto de Egipto, el 54,4 de Argelia; el 48\% de Turquía; el 76\% de Marruecos; el 54,5\% de Túnez. En 1994, el servicio anual de la deuda (intereses y capital) representa el 15,4\% de las exportaciones de Egipto, el $72 \%$ de las de Argelia, el 32\% de las exportaciones de Turquía, el 26\% de las de Marruecos, el 20,5\% de las de Túnez. Al menos algunos de estos porcentajes son difícilmente compatibles con los ajustes exigidos por una liberalización de los intercambios comerciales. Sin embargo, sobre este problema del endeudamiento, la declaración de Barcelona es muy discreta y se contenta con decir: «los socios reconocen las dificultades que la cuestión de la deuda puede representar para el desarrollo económico de los países de la región mediterránea. Se ponen de acuerdo en la necesidad continuar el diálogo con el fin de llegar a progresos en las instancias competentes»(12).

La necesidad de disponer de una financiación que no genere deuda conduce a conceder más importancia que antes a las inversiones extranjeras directas (adquisición de al menos 10\% de las acciones de una empresa) y a los flujos de la ayuda al desarrollo. Entre 1982 y 1992, sobre un total de 265,5 miles de millones de dólares de inversiones directas brutas recibidas por los países en vías de desarrollo, los países del sur y del este del Mediterráneo han recibido 17,8 mil millones, o sea el 6,7\% del total; esta cifra por sí sola ya refleja la escasa atracción que ejerce la región. Durante este periodo y los años siguientes, tres países han recibido un flujo bastante significativo de inversiones extranjeras directas netas, que merece destacarse, esencialmente proveniente de los países europeos: se trata de Turquía, Marruecos y Túnez. Sin embargo, en ninguno de los tres países la inversión extranjera es lo suficientemente importante para ejercer un efecto de arrastre sobre las economías nacionales; sólo representa el $4 \%$ de la inversión global en Turquía, el 6\% en Marruecos y el 9,9\% en Túnez. Los flujos de la ayuda al desarrollo vienen a compensar la falta de dichas inversiones directas sin alcanzar por ello a aliviar el peso de las deudas. Entre 1983 y 1992, Egipto ha recibido 14 mil millones de dólares en forma de donaciones; pero sus inversiones

(12) Europe, Documents no 1974. 
extranjeras disminuyen desde entonces de forma regular. Turquía ha recibido 3,5 mil millones, pero durante este periodo el servicio de su deuda se lleva 21,2 mil millones de dólares. Argelia sólo ha recibido 600 millones de dólares durante este periodo, siendo así que el servicio de su deuda absorbe 16,7 mil millones. Tampoco Túnez sale mejor parado, ya que sólo recibe mil millones de dólares. Marruecos recibe 2,5 pero el servicio de su deuda absorbe 7,6 mil millones de dólares, es decir dos veces más que la suma de las donaciones públicas y de las inversiones directas recibidas durante este periodo (13).

Una comparación entre los países del Magreb y Portugal puede servirnos para concluir este breve estudio financiero. El montante del Producto Nacional Bruto de Portugal es de la misma magnitud que el total de los tres países del Magreb, pero su población es seis veces inferior. Ahora bien, Portugal se ha beneficiado en tres años (1989-1992) de inversiones extranjeras directas netas por un montante de cuatro a cinco veces superior a los registrados en los tres países del Magreb. Por otro lado, la ayuda que ha recibido Portugal de los fondos estructurales europeos ha llegado a representar el $4 \%$ de su Producto Nacional Bruto; incluso después de los aumentos substanciales acordados en Barcelona, esta ayuda a los países del Magreb no sobrepasará el 0,4\% de su PNB. En el primer caso, se trata de hacer converger las economías europeas, en el segundo caso se trata de aportar simplemente una ayuda a países en desarrollo que se quedarán en las puertas de Europa (14). Digamos más bien que si renunciamos a construir fronteras alrededor de Europa y retenemos la imagen de los círculos concéntricos, Portugal y los países del Magreb no pertenecen al mismo círculo concéntrico...

\section{Los datos políticos: economía, paz y democracia}

La declaración de Barcelona comienza expresando el deseo de hacer del Medio-Oriente una zona de paz en la cual «las partes se abstendrán de desarrollar una capacidad militar que vaya más allá de sus legítimas

(13) Fouad ZAIM et Larbi JAIDI, «La dynamique des investissements en Méditerranée» en Euro-Méditerranée, une région à construire, bajo la dirección de Robert BISTOFLI, Publisud, 1995, pp. 289-329.

(14) Bichara KHADER, op. cit. p. 38. et Isabelle BENSIDOUN, op. cit. p. 126. 
necesidades de defensa... favorecerán el establecimiento de relaciones de buena vecindad entre ellas, desarrollarán el Estado de derecho y la democracia en su sistema político» (15). ¡Quién no suscribiría estos deseos! En todo caso constituyen una llamada a completar los datos económicos y financieros con el repaso de algunos datos políticos relacionados con las variables económicas: los conflictos, el Estado, la democracia en esta región del mundo.

Los conflictos ocupan un lugar preponderante en la historia de los países del sur y del este del Mediterráneo durante estas últimas décadas: cinco guerras árabe-israelíes, casi diez años de enfrentamiento entre Irak e Irán, diecisiete años de guerra en el Líbano, conflicto del Sahara occidental que enfrenta a Argelia y a Marruecos, reparto de Chipre, lucha armada contra el PKK en Turquía, insurrección argelina... Ignorar la venta de armas cuando se trata del comercio con estas regiones exige grandes esfuerzos de abstracción. Gracias a la solvencia que le confieren sus excedentes petrolíferos, el Medio-Oriente es el primer importador mundial de armas, y realiza del 30\% al $40 \%$ de las compras internacionales y cerca de la mitad de las compras del Tercer-Mundo. Es el cliente principal de las firmas norteamericanas y europeas, absorbiendo más de las tres cuartas partes de sus ventas en el extranjero. Los encargos de armas de Israel, de Arabia Saudita, Turquía, Egipto, Kuwait y Emiratos Árabes Unidos ascienden a 93 mil millones de dólares de 1993 a 1997, o sea el equivalente al $35 \%$ de las compras del ejército americano en esa misma época. Los problemas de endeudamiento, de joint-ventures y de comercio intrarregional, a los que hemos hecho alusión anteriormente sin encontrar muchas soluciones, han podido sin embargo ser resueltos satisfactoriamente en el sector del armamento. En lo relativo a las deudas baste evocar que, con motivo de la crisis del Golfo, Estados Unidos concedió a Israel 10 mil millones de dólares en créditos de garantía, y condonó 6,7 mil millones de deuda de Egipto; estas medidas de gracia permitieron a ambos países relanzar sus programas de armamento. En lo relativo a las joint-ventures, se puede por ejemplo citar en Egipto la Organización Árabe para la Industrialización (AOI) sostenida por las grandes firmas americanas y europeas de armamento y sus empresas conjuntas con la American Motors, British Aerospace Dynamics y Dassaut. En cuanto al

(15) Europe, Documents no 1974. 
comercio intrarregional, ¿qué país de la región no ha vendido o transferido armas a sus vecinos y sobre todo a Irak? En esta región del mundo el estado endémico de beligerancia detrae muy cuantiosos recursos humanos y materiales del servicio del bienestar de los hombres y mujeres. Los países exportadores de armas no se libran de su gran responsabilidad en esta situación. Recientes investigaciones en estos países confirman que no hay control ético, ni siquiera político, del comercio de armas. Este sigue estando determinado por objetivos comerciales e industriales. Y, lo que es más grave aún, ciertos países del Cercano-Oriente beneficiarios de rentas de guerras se preguntan si las rentas de la paz les serán más provechosas (16).

Si los conflictos armados han marcado duramente a los países del sur y del este del Mediterráneo, igualmente les ha condicionado la implantación de los Estados. El Estado en esta región del mundo tiene una larga historia. Esta historia en el siglo pasado estuvo estrechamente ligada a la de las relaciones económicas y financieras con Europa. Alemania, Inglaterra y Francia vivían entonces bajo un régimen de capitalismo liberal. Transfirieron al Próximo Oriente abundantes capitales y toda esa infraestructura económica que el Khadive Ismael y el Sultán Abdul Medjid llamaban «Europa» y que habían deseando instalar en sus países como se importa una fábrica «llave en mano». Estas transferencias no fueron todas estériles, pero en una región en donde con la caída del Imperio Otomano había desaparecido toda responsabilidad ética, se efectuaron en función de las preferencias europeas. La confianza que concede el liberalismo al carácter espontáneo del desarrollo económico tiene sus límites cuando los deudores empiezan a fallar. Las potencias europeas, protectoras de los acreedores, pusieron en marcha en el Próximo Oriente una administración occidental que se transformó en un verdadero Estado: instalaron en Egipto ministros europeos de Finanzas y Obras Públicas, Caja Financiera Internacional con poderes soberanos en Turquía, administración directa de los países del Magreb. Estos países del este y del sur del Mediterráneo, transformados en Estados nacionales, reconquistaron su libertad financiera, retomaron su independencia monetaria y recuperaron el dominio de su espacio económico por un doble movimiento de nacionalización y de estatalización. Las políticas proteccio-

(16) Véase Françoise CLEMENT, «Les industries d'armement au Moyen-Orient, paix et reconversion» en L'économie de la paix au Proche-Orient, op. cit. T.1, pp. 325-345. 
nistas que hemos enumerado más arriba se inscriben en este doble movimiento (17).

En las dos últimas décadas, un estallido internacional de liberalismo, que deja muy escaso margen de maniobra a los países no integrados en grandes conjuntos, ha incentivado a estos países, en particular a los del sur y del este del Mediterráneo, no sólo a atemperar su política proteccionista sino también a optar por una política liberal radicalmente opuesta: liberalización de los precios, convertibilidad de las monedas, eliminación de los derechos de aduana, privatización del sector público... Se comprende que ciertos Estados sean reticentes a desistir prematuramente de su poder para adoptar un régimen económico liberal sin un proyecto global para ellos y, sobre todo, sin una clara visión del modelo de institución política, y no sólo financiera, apta para salvaguardar los intereses de sus ciudadanos.

Si un papel creciente del sector privado es considerado esencial para el crecimiento económico de los países del sur y del este del Mediterráneo, ¿qué decir del rol que incumbe de manera más amplia a la sociedad civil para el desarrollo de la democracia en estas regiones? (18). Las instituciones internacionales a veces dan la impresión de definir la democracia por el mero hecho de que se celebren elecciones. No hay verdadera democracia sin desarrollo de una sociedad civil, la que forman en particular todos los movimientos asociativos con vocación profesional, económica, social, cultural, religiosa o política. Es preciso fortalecer esta sociedad civil si se quiere promover la democracia en los países del sur y del este del Mediterráneo. La declaración de Barcelona subraya, por su parte: «la contribución esencial que puede aportar la sociedad civil» y el acuerdo de las partes para favorecer los intercambios entre los actores del desarrollo «responsables de la sociedad política y civil, del mundo cultural y religioso, de las universidades, de la investigación, de los medios de comunicación, de las asociaciones, de los sindicatos y de las empresas

(17) Jean DUCRUET, Les capitaux européens au Proche-Orient, PUF. 1964 pp. 441450 .

(18) Véase en particular «Etat, ville et mouvements sociaux au Maghreb et au MoyenOrient,» en Monde arabe, Maghreb-Machrek 1987 n 115. Sarah BEN NEFISSA, «Les lignes regionales et les Associations islamiques en Egypte», en Tiers Monde, janviermars 1995. Guilain DENOEUX et Laurent GATEAU, «L'essor des associations au Maroc: la recherche de la citoyenneté» en Monde arabe, Maghreb-Machrek 1995, nº 150. 
privadas y públicas» (19). Por eso, justamente después de la conferencia de Barcelona, se reunió el Foro civil «Euromed» formado por 1.211 agentes sociales económicos y culturales provenientes de 38 países de la Unión Europea y de los países del sur y del este del Mediterráneo, con el fin de analizar las acciones descentralizadas que están en marcha y examinar nuevos proyectos. No podemos pasar revista aquí a los programas descentralizados que ya están parcialmente terminados. Sólo citaré como ejemplos el Plan de Acción para el Mediterráneo y la actividad de las Asociaciones de ciudades (20).

El Plan de Acción para el Mediterráneo es el fruto de la primera convención mediterránea firmada en Barcelona, en 1975, entre todos los Estados ribereños del Mediterráneo. Reforzado por la conferencia de Génova de 1985, abarca esencialmente los problemas del medio ambiente y se basa en seis centros temáticos. El centro de Atenas gestiona los programas relativos a la contaminación marina y da lugar a varios acuerdos internacionales. El centro de Malta se dedica a la prevención de los riesgos marítimos relativos al transporte de hidrocarburos y de productos químicos. El centro de Túnez vela por la protección de los espacios naturales protegidos y de los parques nacionales. El centro de Split en la antigua Yugoslavia tiene a su cargo los programas de acción prioritaria (acuicultura, erosión de suelos, recursos hídricos etc...). En SophiaAntipolis, en Francia, funciona el centro de actividades del plan azul; el plan azul es el lado «prospectivo» del Plan de Acción para el Mediterráneo. Sus propuestas son tenidas en cuenta y relanzadas por el Banco Mundial y el Banco Europeo de Inversiones.

No hay una asociación de ciudades del Mediterráneo; pero hay numerosas asociaciones que comparten este papel. A título de ejemplo, podemos citar: la Federación Mundial de Ciudades Unidas, el Consejo de Ayuntamientos y de Regiones de Europa, la Organización de Ciudades Árabes creada en 1967 a partir de Kuwait, la Unión de Ciudades Africanas creada en 1975 a partir de Rabat, la Organización de Ciudades y de Capitales Islámicas creada en 1980 a partir de La Meca. Las actividades de estas asociaciones son diversas:

(19) Europe, Documents no 1974.

(20) Sobre esta cooperación cultural véase en particular. La Méditerranée réinventée, sous la direction de Paul BATA, Edit, La Découverte, 1992 et La Méditerranée inquiète, sous la direction de Xavier GIZARD, Edit de l'Aube, 1995. 
cooperación técnica, transferencias de experiencias y de tecnologías municipales, financiación de proyectos puntuales. Existe una toma de conciencia cada vez mayor acerca de la competencia propia de las ciudades y de las regiones, de su aptitud para informar y para hacer participar a la población en sus programas, ya se trate de la protección del entorno, del crecimiento urbano, de la acogida de los inmigrantes. Los programas MEDCITÉS, lanzados en Barcelona en 1991 con el apoyo del Banco Mundial, están concebidos a partir de 18 ciudades, una por país ribereño del Mediterráneo.

Si estos programas descentralizados todavía son limitados y no disponen siempre de los recursos deseables, sin embargo son importantes porque han creado una corriente favorable a las actividades de las ONGs que se multiplican y que representarán el día de mañana un sector nada despreciable en el ámbito de las relaciones entre Europa y los países del sur y del este del Mediterráneo.

\section{Conclusión}

No puede haber una conclusión propiamente dicha a lo que simplemente ha pretendido ser un estado de la cuestión para aclarar una propuesta de colaboración entre los países del sur y del este del Mediterráneo. Me voy a contentar con exponer algunas reflexiones finales.

La propuesta europea de constitución de zona de libre comercio, sean cuales fueran sus límites, al menos tiene el mérito de existir. Por lo menos, significa que Europa intenta no cerrarse sobre sí misma, a pesar de los riesgos de exclusión que presentan los acuerdos de Schengen, el mercado común y la moneda única para aquellos países que no formaron parte de la Unión Europea. Jacques Delors recordaba oportunamente en las últimas Semanas Sociales de Francia que «Europa es el primer donante de ayudas al mundo en todos los sectores y en todos los continentes» (21). Sin una apertura al resto del mundo, cabe preguntarse si Europa seguiría siendo todavía Europa. La importancia de esta apertura ha sido muy bien comprendida por Felipe González, quien escribió sobre la aportación de su país a Europa: «España ha aportado a Europa la dimensión de siglos de historia y de cultura compartidas con el mundo iberoamericano, la dimensión mediterránea, en particular la mirada hacia

(21) Semaines Sociales de France 1996, Quelle Europe?, Bayard 1997 p. 108. 
el Magreb...»(22). Más significativa todavía es la postura de Hartmut Elsenhans: poco convencido del interés económico de un compromiso europeo con el Mediterráneo sur, mantiene sin embargo la necesidad de este compromiso en razón del interés superior de mantener la cohesión y el equilibrio de Europa amenazada, en su opinión, por una «deportación geográfica» hacia el norte (23).

Si la propuesta europea de constitución de una zona de libre comercio no ha conseguido de entrada la adhesión de todos los países afectados, ante todo es porque se presenta, quiérase o no, como un medio para Europa de protegerse contra las migraciones y de aumentar sus exportaciones industriales: de nuevo la propuesta de una Europa de los mercaderes. Las propuestas políticas y sociales no han dado lugar a proyectos concretos y, por tanto, parecen platónicas; sin duda lo seguirán siendo mientras no exista una verdadera Europa política. Esta ausencia de unanimidad viene quizás también del hecho de que el libre comercio de productos manufacturados no es la preocupación principal de un cierto número de países del sur y del este del Mediterráneo, más preocupados por el desarrollo de la economía de los hidrocarburos como materia prima de la industria química, por asegurar y gestionar sus recursos hídricos, por reducir su dependencia alimenticia cada vez más inquietante, y por desarrollar su economía turística.

En cualquier caso, a falta de una adhesión unánime de los países del sur y del este del Mediterráneo a la propuesta europea, nos encontramos hoy ante una serie de acuerdos bilaterales que ponen en marcha estatutos muy diversos: Chipre y Malta han sido llamados a adherir a la Unión Europea; Turquía, desgraciada candidata a esta Unión, al menos es socio de una unión aduanera; Israel está dotado de un régimen especial; Marruecos y Túnez han firmado acuerdos de asociación personalizados; los otros países están buscando plazos, compromisos sobre los intercambios agrícolas y sobre el montante de las subvenciones. Libia permanece fuera de toda negociación.

Estos modestos acuerdos bilaterales han decepcionado a los que ven en el Euro-Mediterráneo «una región por construir». Pero el Mediterráneo no es

(22) Felipe GONZÁLEZ, «L'Espagne en Europe, 1'Europe en Espagne» in Projet ${ }^{\circ}{ }^{2} 250$, été 1997, p. 20.

(23) Hartmut ELSENHANS, «Enjeux méditerranéens et cohésion européenne» en Euro-Méditerranée, une région à construire, op. cit., p. 127. 
un continente; es un mar. Puede poner en relación a los pueblos; no puede soldarlos. Geografía e historia mediterráneas sugieren cooperaciones interactivas pero disuaden de toda anexión, aunque sólo sea económica. Los países ribereños del Mediterráneo, muy diferentes por su situación y por su política, no pueden actualmente ser considerados como un todo; no deben tampoco aislarse de los espacios que los rodean. En cada una de las riberas del Mediterráneo desembocan ríos que van cargados de problemas originados tierra adentro, en un área muchísimo más vasta que la del litoral. Turquía, por ejemplo, no es simplemente un país ribereño del Mediterráneo; tiene relaciones privilegiadas con las nuevas repúblicas de Asia central. No es ante todo su ribera mediterránea la que define a Egipto, sino que el valle del Nilo y los problemas del Sudán son sus problemas. Argelia y Marruecos no se enfrentan sobre la pesca sino sobre el Sahara occidental. No son los sucesos del Mediterráneo sino la revolución iraní y las guerras del Golfo los que, en la última década, han revolucionado en muchos aspectos los datos de los países del sur y del este del Mediterráneo. No cortemos a estos países de sus hinterlands; con frecuencia, es este hinterland el que les da su verdadero peso y el que de alguna manera determina su futuro.

No debería ser necesario añadir que, si bien es evidente que existe una cultura mediterránea, ésta no puede aislarse. Con frecuencia se ha hecho notar que, si dejamos a un lado a Turquía, el Mediterráneo apenas aparece en la cultura árabe-musulmana como espacio de identificación: el territorio fundador no es el mar, sino el desierto; el espacio de referencia es la Umma, la comunidad de los creyentes, y no el mundo europeo secularizado. Pero el hecho de que la cultura mediterránea no ocupe un lugar predominante en el este y en el sur del Mediterráneo no significa que no tenga un lugar en esa región. De hecho tiene un papel equilibrador de gran importancia. Bien lo saben los libaneses, que preservan con cuidado la historia de su costa fenicia, aun cuando deba ser integrada hoy día en una historia más larga; Taha Hussain lo comprendía al exigir que hubiera un lugar para el Mediterráneo en «el futuro de la cultura egipcia». El Islam fundamentalista, por el contrario, intenta situarse en una perspectiva de identidad monolítica, rechazando la apertura mediterránea. Las relaciones económicas y culturales entre las dos riberas del Mediterráneo son de gran importancia; pero es preciso afrontarlas con realismo. Como escribía Edgar Pisani: «El Medite- 
rráneo nunca será una región. Ojalá pueda transformarse en una inter-región, un lugar de tensiones dominadas... Hay que crear las condiciones del intercambio mercantil, así como las de la circulación de personas, pero es preciso también ocuparse de comunicar, de buscar juntos, y de confrontar las visiones del mundo...»(24).

(24) Edgar PISANI, ibid., p. 7. 